\title{
Development of Novel Polyimide Build-up Material
}

\author{
Takashi Itoh, Shigeru Tanaka, Kanji Shimoohsako, \\ Masaru Nishinaka and Mutsuaki Murakami \\ Electronics Research Laboratories, \\ Electronics R\&D Center, KANEKA Corporation, \\ 5-1-1, Torikai - Nishi, Settsu, OSAKA 566-0072, JAPAN \\ Takashi_Ito@kn.kaneka.co.jp
}

Keywords: polyimide, build-up, printed wiring board

\section{Introduction}

Recently, electronic equipment has been required to have many functions and a high processing speed. To meet these requirements, high performance CPUs have evolved to have high clock frequencies and high $\mathrm{I} / \mathrm{O}$ numbers. To mount the CPUs to the substrate, the flip chip attachment method is usually adopted to exhibit the maximum performance of CPUs and it is necessary for the substrates to a have high wiring density. Build-up PWBs whose circuits are formed by the semi-additive method have been used for these substrates.

Next generation build-up PWBs for next generation CPUs, which are expected to have higher $\mathrm{I} / \mathrm{O}$ numbers, are required to have fine-pitched circuits of less than 20 micron $\mathrm{L} / \mathrm{S}$ (Line and Space). For the fabrication of the fine-pitched circuits, it is important for the build-up material on which the fine-pitched circuits are formed to have as a small amount of surface roughness as possible and an ability to adhere the circuits without peeling off.

Epoxy resin has been mainly used for build-up material. The epoxy type build-up material is processed to make the material's surface roughen to firmly adhere the circuit by anchor effect. For the fabrication of next generation fine-pitched circuits of less than 20 micron L/S, new build-up material is desired which has a smaller amount of surface roughness than the existing material and good adhesion with the circuit. Furthermore new build-up material is needed to have low CTE (Coefficient of Thermal Expansion), low dielectric property, which improve the electrical reliability or electrical properties of build-up PWB.

For the development of next generation build-up material, we started to develop a new polyimide build-up material expecting superior properties based on the properties of polyimide resin that has been used for electric insulation material. As a result of this investigation, we could develop a novel thermosetting polyimide build-up material that meets the requirement mentioned above. In this paper, the thermal properties, the dielectric properties around gigahertz $(\mathrm{GHz})$, the peel strength of electro-less plated copper layer on the materials, the processability of fine-pitched circuit by semi-additive process and LASER via processability are evaluated.

\section{Target Properties}

First in the development, the target properties for new build-up material were designed.

-A CTE less than $50 \mathrm{ppm}$

-A dielectric loss (Df) of less than 0.010 at $1 \mathrm{GHz}$ -A mechanical strength over $100 \mathrm{MPa}$

-Flame resistance without a halogenated compound

-The processability of a fine-pitched circuit less than $20 \mathrm{micron} \mathrm{L} / \mathrm{S}$ by semi-additive process

\section{Methods and Results}

\subsection{Formation of finely roughened build-up material's surface}

To fabricate the fine-pitched circuit by semi-additive process, the build-up material is needed to have the surface with a small amount of surface roughness and exhibit a high peel strength with an electro-less plated copper layer. In this investigation the replica method is used to make a finely roughened surface of the material. In the replica method, finely roughened copper foil surface is transcribed to the surface of the build-up 
material, i.e. the copper foil is laminated to the build-up material using vacuum press machine and then the copper foil is removed from the build-up material by an etching process. By using copper foil having different surface roughness, the surface roughness of build-up material can be controlled.

Fig. 1 shows a SEM image of the typical material's surface after removing the copper foil having surface roughness of 1.5 microns and applying de-smear treatment, consisting of sodium permanganate. Fig. 2 shows a surface roughness measurement chart of the same surface measured by New View 5000 3-D Surface Profilers (Zygo corporation product). Finely roughened surface is observed from Fig. 1 and the surface roughness was evaluated to have an $\mathrm{Rz}$ of 1.1 micron and an $\mathrm{Ra}$ of 0.17 micron.

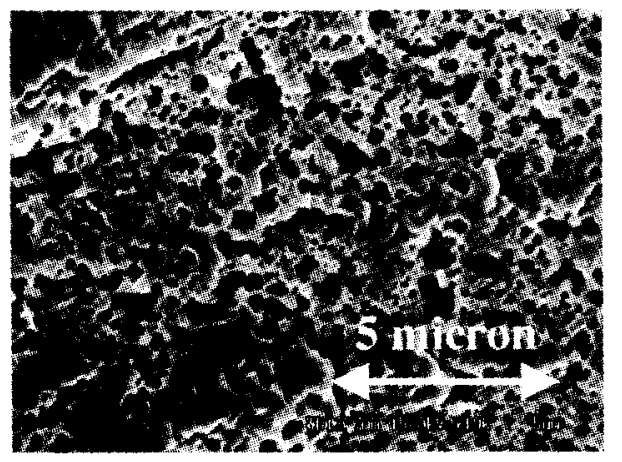

Fig. 1. SEM image of the build-up material's surface made by the replica method

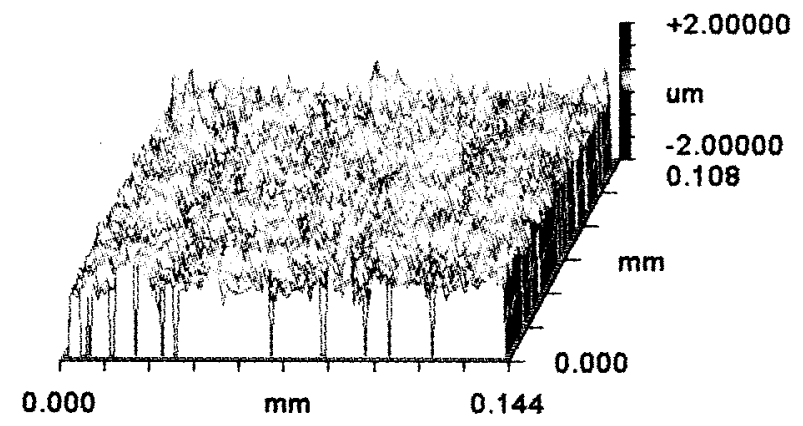

Fig.2. 3D Surface Profile of the build-up material's surface $(R z=1.1$ micron and $R a=0.17$ micron $)$

3.2 Measurement of peel strength

\subsection{Measurement of peel strength}

Electro-less copper was plated on the surface of the build-up material on which the replica was formed. After electrolytic copper was deposited on up to 18 micron, peel strength was measured according to JIS C6471.

In Fig. 3, the relation between the surface roughness of the build-up material using various copper foil and the corresponding peel strength is shown. From Fig. 3, the peel strength is observed to rise with increasing surface roughness and shows higher than $7 \mathrm{~N} / \mathrm{cm}$ even with a low $\mathrm{Rz}$ around 1 micron. We suppose that this high peel strength is caused not only by the anchor effect but also by the chemical interaction between the polyimide resin and the electro-less copper.

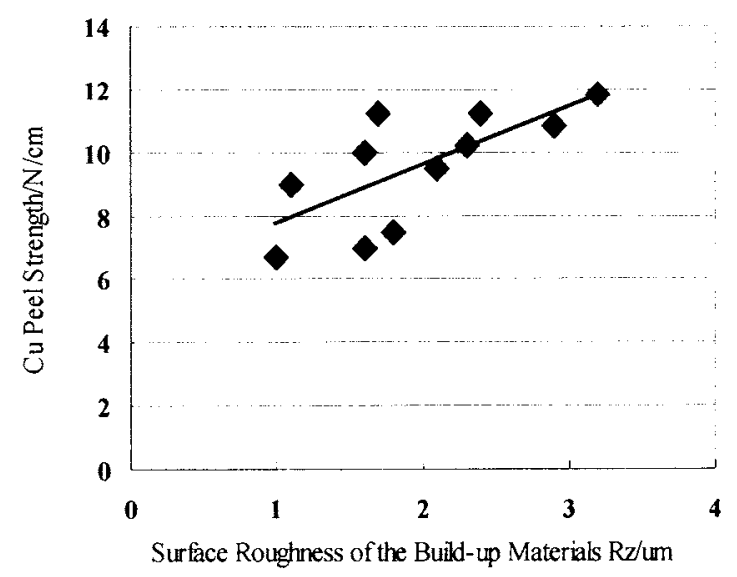

Fig.3. The relation between the surface roughness and peel strength

The results of detail study regarding peel strength are shown in Table 1. Despite a small amount of surface roughness $\mathrm{Rz}$ around 1 micron, the peel strength shows enough high for practical use even after the conditioning of PCT or aging.

Table 1. Results of peel strength

\begin{tabular}{|c|c|}
\hline Conditions & Peel strength \\
\hline As received & $9 \mathrm{~N} / \mathrm{cm}$ \\
\hline After PCT & $6 \mathrm{~N} / \mathrm{cm}$ \\
$(96 \mathrm{hr} / 121 \mathrm{dC} / 100 \% \mathrm{RH})$ & \\
\hline After aging $(240 \mathrm{hr} / 150 \mathrm{dC})$ & $7 \mathrm{~N} / \mathrm{cm}$ \\
\hline
\end{tabular}

The surface roughness is an $\mathrm{Rz}$ of 1.1 micron and an $\mathrm{Ra}$ of 0.17 micron.

\subsection{Processability of fine-pitched circuit}

The processability of fine-pitched circuit is evaluated according to the process shown in Fig. 4. Copper foil, build-up material and core BT substrate were stacked and laminated using a vacuum press machine under the condition of $1 \mathrm{hr} / 3 \mathrm{MPa} / 180 \mathrm{dC}$. The copper foil is then removed by an etching process from the laminate, and then de-smear and electro-less copper plating is applied onto the surface of the build-up material. 


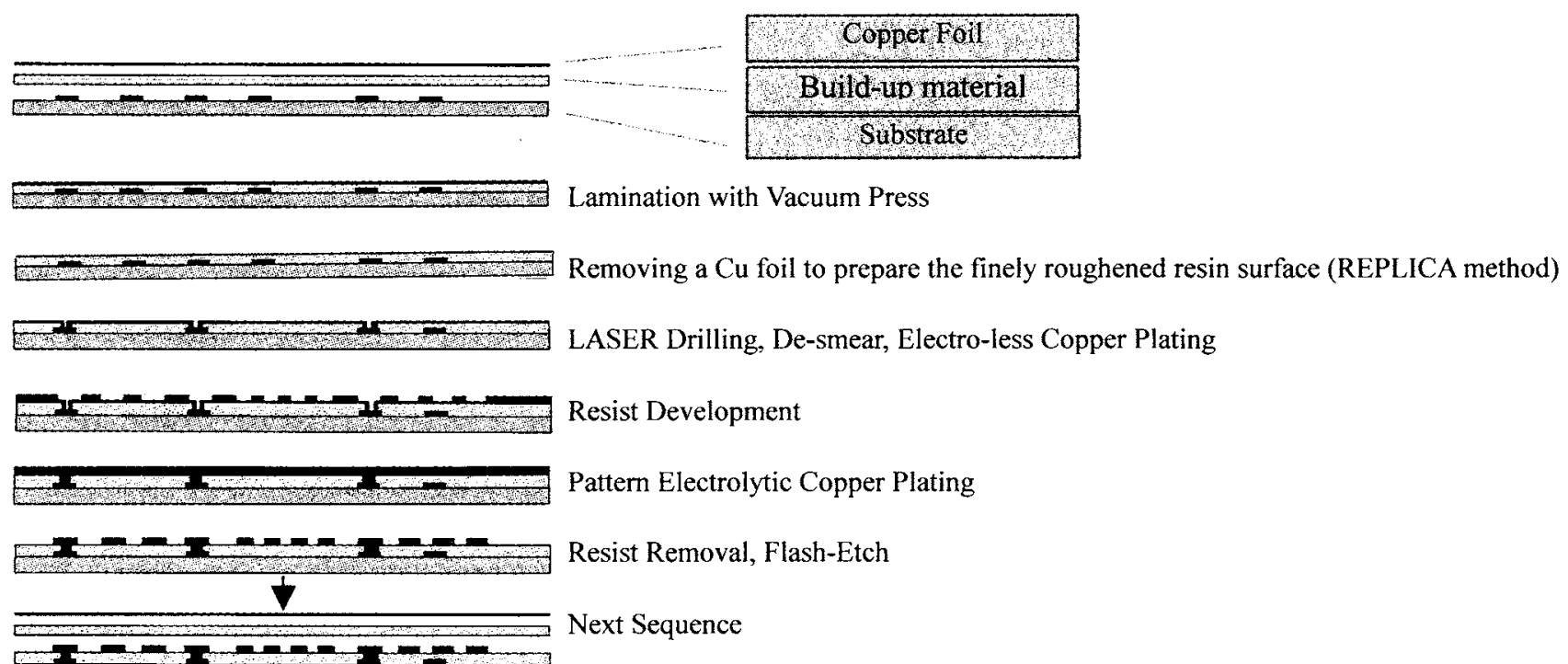

\section{$\vdots$}

Fig.4. Typical manufacturing process of build-up PWB

Dry film resist (DFR) used in the resist - development process, was Sunfort (TM), which was supplied by Asahi Kasei Electronics Materials $\&$ Device. The DFR is processed to make the pattern of resist materials, and then pattern electrolytic copper plating is applied. After removing the resist pattern the flash etching process consisting of sulfuric acid-hydrogen peroxide is applied.

The SEM image of 20 micron pitched copper circuit is shown in Fig. 5. The circuits are observed to have a good rectangular shape; therefore the build-up material is proven to have a good compatibility for the fine-line fabrication with the replica method. Furthermore the space area between two copper lines was analyzed by EDX and it was confirmed that no residue of $\mathrm{Cu}$ element was observed. Superior insulation property between the lines can be expected.

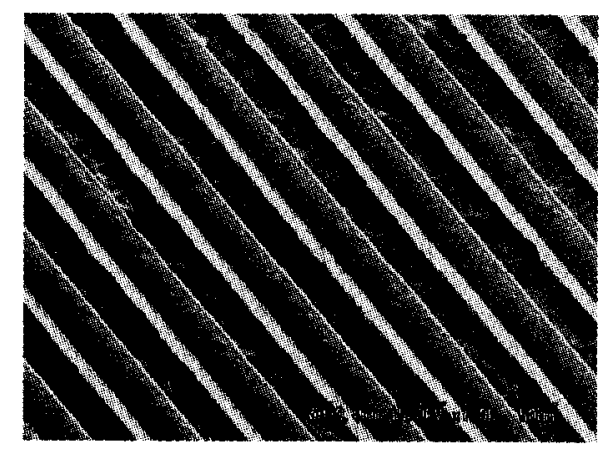

Fig.5. SEM image of 20 micron $(\mathrm{L} / \mathrm{S}=10 / 10)$ pitched circuit

\subsection{Laminate property}

Fig. 6 show the cross sections of laminating build-up material 2 to the copper circuit fabricated on the build-up material 1. The laminating process was carried out under the condition of $1 \mathrm{hr} / 3 \mathrm{MPa} / 180^{\circ} \mathrm{C}$ using a vacuum press. No void can be observed near the bottom of the circuit, the build-up material is found to fill well into the space area between the circuits and to have a good laminate property.

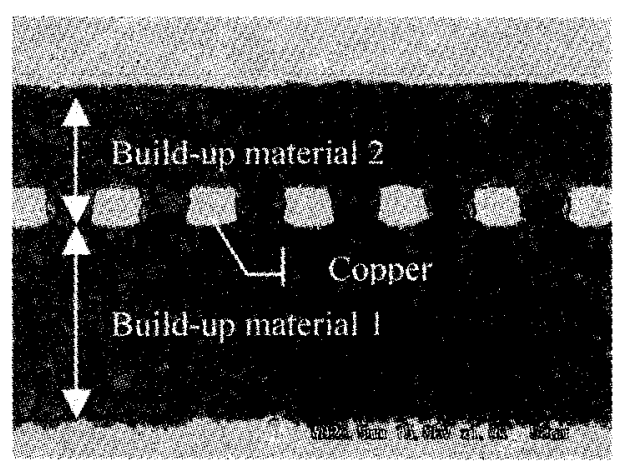

Fig.6. Cross section of laminate (20 micron pitched circuit)

\subsection{LASER via formation}

Fig. 7 shows a SEM image of 50 micron via drilled by UV-YAG LASER and Fig. 8 shows a cross section after plating. Fine shape of the via is observed from the picture, it was found that the material is supposed to be suitable for LASER via formation. 


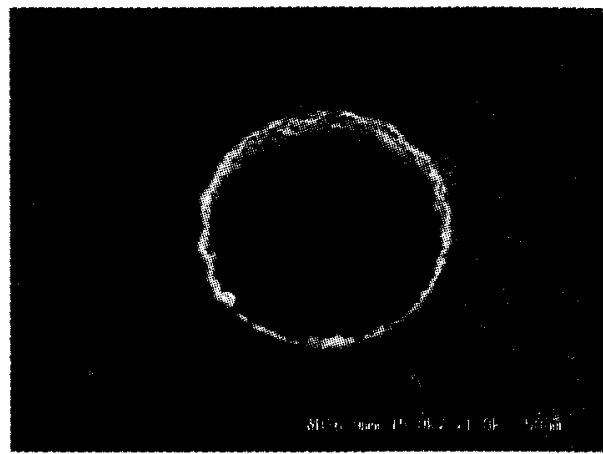

Fig.7. SEM image of via formed by UV-YAG LASER (before plating)

Table 2. Properties for the new build-up material

\begin{tabular}{|c|c|c|}
\hline & Conditions & $\begin{array}{l}\text { Measured } \\
\text { values }\end{array}$ \\
\hline Material type & --- & Film \\
\hline Water absorption & $\mathrm{D} 24 / 23$ & $0.7 \%$ \\
\hline $\begin{array}{l}\text { Glass transition } \\
\text { temperature }\end{array}$ & $\begin{array}{l}\text { TMA } \\
\text { DMA }\end{array}$ & $\begin{array}{l}150 \mathrm{dC} \\
167 \mathrm{dC}\end{array}$ \\
\hline $\begin{array}{l}\text { Coefficient of } \\
\text { thermal expansion }\end{array}$ & $-55-125 \mathrm{dC}$ & $45 \mathrm{ppm}$ \\
\hline $\begin{array}{l}\text { Thermal } \\
\text { decomposition } \\
\text { temperature }\end{array}$ & TGA & $>400 \mathrm{dC}$ \\
\hline Tensile modulus & \multirow{3}{*}{ RT } & $4.1 \mathrm{GPa}$ \\
\hline Tensile strength & & $100 \mathrm{MPa}$ \\
\hline Elongation & & $6 \%$ \\
\hline Dielectric constant & \multirow{2}{*}{$\begin{array}{c}1 \mathrm{GHz} \\
\text { Resonance cavity method }\end{array}$} & 3.0 \\
\hline Dielectric loss & & 0.010 \\
\hline $\begin{array}{l}\text { Insulation } \\
\text { resistance }\end{array}$ & $\begin{array}{c}\text { HAST, } 3.3 \mathrm{~V} \text { biased, } \\
\text { thickness of dielectric is } 20 \\
\text { micron }\end{array}$ & $\begin{array}{l}>200 \mathrm{hr} \\
>\quad 1.0 \mathrm{E}+9 \\
\mathrm{ohm}\end{array}$ \\
\hline Volume resistance & $\begin{array}{c}\text { RT } \\
125 \mathrm{dC}\end{array}$ & $\begin{array}{l}>1.0 \mathrm{E}+16 \\
\mathrm{ohm} * \mathrm{~cm} \\
>1.0 \mathrm{E}+16 \\
\mathrm{ohm}^{*} \mathrm{~cm}\end{array}$ \\
\hline $\begin{array}{l}\text { Peel strength with } \\
\text { electro-less copper } \\
\text { (Replica method) }\end{array}$ & $\begin{array}{c}\text { Thickness } 18 \text { micron } \\
\text { As received } \\
\text { After } \mathrm{PCT} \\
(96 \mathrm{hr} / 121 \mathrm{dC} / 100 \% \mathrm{RH}) \\
\text { After aging }(240 \mathrm{hr} / 150 \mathrm{dC})\end{array}$ & $\begin{array}{l}9 \mathrm{~N} / \mathrm{cm} \\
6 \mathrm{~N} / \mathrm{cm} \\
7 \mathrm{~N} / \mathrm{cm}\end{array}$ \\
\hline $\begin{array}{l}\text { Solder heat } \\
\text { resistance }\end{array}$ & JEDEC LV3 & Pass \\
\hline $\begin{array}{l}\text { Flammability } \\
\text { rating }\end{array}$ & UL-94 & $\begin{array}{l}\text { V0 } \\
\text { equivalent } \\
\text { Halogen } \\
\text { free }\end{array}$ \\
\hline
\end{tabular}

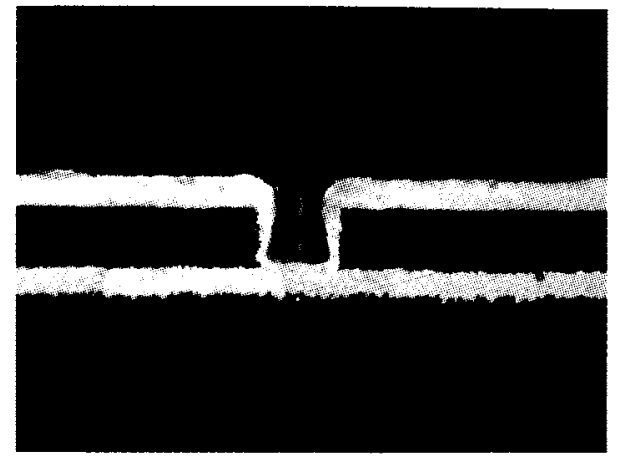

Fig.8. Cross section of via formed by UV-YAG LASER (50 micron diameter, after plating)

\subsection{Properties for the new build-up material}

The properties for the new build-up material are summarized in Table 2. Remarkable electrical properties such as low dielectric loss of 0.010 and high insulation resistance in HAST are recognized. High volume resistance of over $1.0 \mathrm{E}+16 \mathrm{ohm} * \mathrm{~cm}$ is recognized even in high temperature of $125^{\circ} \mathrm{C}$, at which temperature is expected as the junction temperature of next generation semiconductors and over $5.0 \mathrm{E}+12 \mathrm{ohm} * \mathrm{~cm}$ of volume resistance is required for the next generation build-up material [1].

Excellent thermal and mechanical properties are recognized, i.e. low coefficient of thermal expansion as less as 45ppm, high thermal decomposition temperature over $400^{\circ} \mathrm{C}$, tensile strength as high as $100 \mathrm{MPa}$, and $\mathrm{V} 0$ equivalent without halogenated compound. The origin of these properties is supposed to be based on the properties of polyimide.

\section{Conclusion}

We have developed a new thermosetting polyimide build-up material, which shows superior electrical and mechanical properties, and we believe that this material has a potential for next generation build-up material.

\section{Reference}

1. K.Kobayashi, K.Yamanaka, H.Mori, Y.Tsukada, Micro Electronics Symposium 2001, p355 (in Japanese). 